\title{
O ARTISTA COMO UM NOVO BÁRBARO NOS ESCRITOS DE WALTER BENJAMIN
}

Rafael A. Belo

\begin{abstract}
RESUMO
O presente artigo sustenta-se na obra de Walter Benjamin, e possui o objetivo de compreender o artista dentro da concepção de nova barbárie apresentada pelo filósofo no texto Experiência e Pobreza. Em um primeiro momento buscouse explicitar a relação entre a barbárie e a modernidade como alegoria destacada pelo autor. Em um segundo momento a cidade moderna é apresentada como cenário, sendo especificamente palco de uma fantasmagoria e pobreza de experiência. Para ilustrar a presença do artista na cidade moderna discute-se a figura de Charles Baudelaire, que segundo Benjamin foi por quem pela primeira vez Paris se torna objeto da poesia lírica. Finalmente, aborda-se a dimensão política e a função revolucionária da arte, tomando como uma das referências a visão de Benjamin sobre a arte de Bertolt Brecht. Como resultado da reflexão proposta compreende-se que a arte, no sentido de uma nova e positiva barbárie, deve proporcionar a experiência messiânica de ruptura, na medida em que encorpa uma luta que não é somente sua e de sua geração, mas também de gerações passadas.
\end{abstract}

Palavras-chave: Walter Benjamin. Nova barbárie. Artista. Modernidade. Arte.

\section{THE ARTIST AS A NEW BARBARIAN IN WALTER BENJAMIN'S WRITINGS}

\begin{abstract}
This article is based on the work of Walter Benjamin and aims to understand the artist within the concept of new barbarism presented by the philosopher in the text Experience and Poverty. At first, we sought to make explicit the relationship between barbarism and modernity as an allegory highlighted by the author. In a second moment the modern city is presented as a scenario, being specifically the scene of a ghostly and poverty of experience. To illustrate the artist's presence in the modern city, we discuss the figure of Charles Baudelaire, who according to Benjamin was that whom for the first time Paris becomes the object of lyric poetry. Finally, it addresses the political dimension and revolutionary function of art, taking as one of the references Benjamin's view of Bertolt Brecht's art. As a result of the proposed reflection it is understood that art, in the sense of a new and positive barbarism, must provide the messianic experience of rupture, insofar as it embodies a struggle that is not only yours and of your generation, but is also of generations past.
\end{abstract}

Keywords: Walter Benjamin. New barbarismo. Artist. Modernity. Art.

Mestre e doutorando em Educação. Professor da Universidade Federal de Alagoas (UFAL), Campus Arapiraca. Integrante do Grupo de Estudo e Pesquisa História da Educação, Cultura e Literatura (GEPHECL) do Centro de Educação/UFAL. Brasileiro, residente em Maceió-AL. Email: rafaelbelo paz@hotmail.com 


\title{
Introdução
}

Sustentado na obra de Walter Benjamin, o presente artigo objetiva compreender o artista dentro da concepção de nova barbárie apresentada por este pensador no texto Experiência e Pobreza. Neste escrito, Benjamin (1994b) aborda o enfraquecimento da experiência em seu caráter coletivo, como característica de uma modernidade que sobrepõe a técnica ao ser humano. Diante desta pobreza de experiência, Benjamin (1994b) vê a necessidade e a possibilidade do surgimento de uma nova e positiva barbárie, com um sentido e força criativa.:

\begin{abstract}
Sim, é preferível confessar que essa pobreza de experiência não é mais privada, mas de toda a humanidade. Surge assim uma nova barbárie. Barbárie? Sim. Respondemos afirmativamente para introduzir um conceito novo e positivo de barbárie. Pois o que resulta para o bárbaro dessa pobreza de experiência? Ela o impele a partir para a frente, a começar de novo, a contentar-se com pouco, a construir com pouco, sem olhar nem para a direita nem para a esquerda. (BENJAMIN, 1994b, 115-116)
\end{abstract}

Por outro lado, a concepção de barbárie mais explicitada na obra de Benjamin é a de uma catástrofe, sobretudo por causa de sua alegoria acerca do Anjo da História, presente na tese IX Sobre o conceito de história (BENJAMIN, 2005). Esta concepção relaciona-se com crítica à modernidade feita pelo autor, apresentada aqui na seção: $A$ barbárie e a modernidade como alegoria.

$\mathrm{Na}$ seção seguinte, apresenta-se o cenário desta barbárie: a cidade moderna, a qual Paris é tomada como símbolo. Da sociedade moderna, a cidade é vitrine e palco do que Benjamin (2007b) chama de "universo de uma fantasmagoria", por incentivar a dimensão privada da experiência (Erlebnis), própria da lógica capitalista, em detrimento da em experiência em seu caráter coletivo (Erfahurung). 
Exposto a cidade como cenário da pobreza de experiência na modernidade, aborda-se especificamente a (nova) barbárie como ato criador, na seção subsequente. Para tal, ela é diferenciada do novo como mera "galvanização", explicada por Benjamin através de sua percepção de "fantasmagoria" na crítica político-social dos quadros do pintor belga James Ensor. Dando continuidade a compreensão de (nova) barbárie do Experiência e Pobreza, discute-se a influência de Nietzsche em Benjamin, sobretudo a partir da noção de "homem histórico" descrito por Nietzsche (1999) nas Considerações extemporâneas.

Por fim, na seção $O$ artista na cidade moderna apresenta-se a possibilidade de compreensão do artista como um dos autores da nova barbárie na cidade moderna. A fim de ilustrar a presença do artista na modernidade discute-se a figura de Charles Baudelaire, que para Benjamin (2000) representa o declínio da figura tradicional do artista, aquele que tomando a cidade como objeto de sua arte, e que torna heroico os acontecimentos de sua existência.

A sessão final deste artigo chama-se $A$ arte e o artista em Walter Benjamin: a política e a função revolucionária da arte. Argumenta-se acerca da dimensão política e da função revolucionária da arte, ou da arte entendida como nova barbárie. Para tanto, toma-se como uma das referências a visão de Benjamin sobre a arte de Bertolt Brecht. As reflexões propostas ao longo do texto permite compreender que, no sentido de uma nova e positiva barbárie, a arte,ou o artista na modernidade, deve proporcionar a experiência messiânica de ruptura, incorporando uma luta que também é de gerações passadas.

\section{A barbárie e a modernidade como alegoria}

A barbárie descrita com uma catástrofe que sem cessar amontoa escombros sobre escombros e os arremessa aos pés do Anjo da História, formando um amontoado até o céu, enquanto este, com o rosto voltado para o passado, é impelido para o futuro, com suas asas abertas pela força de uma tempestade, é a alegoria mais conhecida do pensador judeu alemão Walter Benjamin.

Mestre e doutorando em Educação. Professor da Universidade Federal de Alagoas (UFAL), Campus Arapiraca. Integrante do Grupo de Estudo e Pesquisa História da Educação, Cultura e Literatura (GEPHECL) do Centro de Educação/UFAL. Brasileiro, residente em Maceió-AL. Email: rafaelbelo paz@hotmail.com 
A arte, e de maneira particular a imagem, assume uma grande importância no pensamento Benjamin, de modo que para Sigrid Weigel (2010, p. 21) "le concept d'image institue une sorte de leitmotiv dans ses écrits"1.

A força desta imagem, descrita há pouco, presente na tese IX Sobre 0 conceito de história, marcou a imaginação de uma época, segundo Michel Löwy (2005, p.87) por tocar profundamente na "crise da cultura moderna" e, também, por parecer em uma dimensão profética ter sido um prenúncio trágico de Auschwitz e Hiroshima, e de tantas outras catástrofes que marcaram a história da humanidade desde da publicação da tese em 1940, após a morte do autor.

Os escombros, contudo, não têm apenas um sentido literal, referem-se, sobretudo, ao resultado da cultura de dominação que faz prevalecer a "história" do opressor como um triunfo natural e linear, ao passo que destrói a memória das gerações passadas e a força revolucionária da sua experiência coletiva, silenciando definitivamente as vozes que vêm do passado. O Anjo da História, diante desse cenário, "gostaria de demorar-se e despertar os mortos e juntar os destroços" (BENJAMIN, 2005, Tese IX, p.89), mas é impedido pela força da tempestade chamada progresso.

Esta interpretação nasce da intencionalidade dada por Benjamin à obra pintada por Paul Klee, Angelus Novus (1920, Museu de Jerusalém²). Para Löwy (2005, p. 88), trata-se de uma alegoria, pois seus elementos não têm, fora do papel, o significado que é atribuído por Benjamin, tratando-se "fundamentalmente da projeção de seus próprios sentimentos e ideias sobre a imagem sutil e despojada do artista alemão".

Para Löwy, (2005) Le fleurs du mal, livro de poemas do francês Charles Baudelaire, com suas passagens poéticas, teria, provavelmente, inspirado Benjamin na escrita da tese IX. Esse livro foi proibido pouco tempo depois da sua publicação em junho de 1857 por ofensa à moral pública e, em sua segunda edição, no ano de 1861, foi incluído o conjunto de poemas intitulado Tableaux

\footnotetext{
1 "O conceito de imagem institui uma espécie de tema condutor de seus escritos" (tradução nossa).

2 https://www.imj.org.il/en/collections/199799

Mestre e doutorando em Educação. Professor da Universidade Federal de Alagoas (UFAL), Campus Arapiraca. Integrante do Grupo de Estudo e Pesquisa História da Educação, Cultura e Literatura (GEPHECL) do Centro de Educação/UFAL. Brasileiro, residente em Maceió-AL. Email: rafaelbelo paz@hotmail.com
} 
parisiens, onde o poeta aparece como precursor da cidade na modernidade (JUNQUEIRA, 2012). Apesar do rigor dos tradicionais versos alexandrinos ${ }^{3}$, 0 livro de Baudelaire é considerado polêmico pela forma com que aborda temas que remetem à vida na cidade.

Como exemplo dos versos que teriam inspirado a interpretação de Benjamin do quadro Angelus Novus, Löwy (2005) cita o fragmento de Une gravure fantastique, que lhe parece uma descrição da visão que o Anjo tem do passado da humanidade:

Le cimetière immense et froid, sans horizon,

Où gisent, aux lueurs d'un soleil blanc et terne,

Les peuples de l'histoire ancienne et moderne.

O imenso e frio cemitério sem limite,

Onde repousa, à luz de um sol pálido e terno,

Quanto povo existiu, desde o antigo ao moderno.

Charles Baudelaire

$\mathrm{Na}$ época em que Benjamin adquiriu esta obra, em 1921, quando inicialmente chama o Anjo de protetor da Cabala, seu amigo Gerhard Scholem, Ihe envia um poema, Salutation de l'Ange, com a escrita de um "eu lírico" e como expressão da leitura da imagem de Klee do ponto de vista do Anjo (WEIGEL, 2010).

Minhas asas estão prontas para o voo,
Se pudesse, eu retrocederia
Pois eu seria menos feliz
Se permanecesse imerso no tempo vivo. ${ }^{4}$

Gerhard Scholem

Embora o poema tenha causado certa irritação em Benjamin, ele o citou quase vinte anos depois na epígrafe na tese IX, quando, após anos de fascínio pela imagem, ela aparece como alegoria no seu trabalho teórico sobre o conceito

\footnotetext{
${ }^{3}$ São versos formados por doze sílabas poéticas. Conhecidos também por Alexandrino Clássico ou Alexandrino Francês.

${ }^{4}$ Tradução de Sergio Paulo Rouanet em Benjamin (1994a).

Mestre e doutorando em Educação. Professor da Universidade Federal de Alagoas (UFAL), Campus Arapiraca. Integrante do Grupo de Estudo e Pesquisa História da Educação, Cultura e Literatura (GEPHECL) do Centro de Educação/UFAL. Brasileiro, residente em Maceió-AL. Email: rafaelbelo paz@hotmail.com
} 
de história. Tal irritação advém do entendimento da contradição dos versos, uma vez que sendo a língua dos anjos de tal modo diferente da língua humana, tal tipo de conversação não seria possível (WEIGEL, 2010). Assim, em resposta à gentileza de Scholem, Benjamin responde: “T'ai-je dit un mot de son 'salut'? La langue angélique compete au nombre de ses merveilles l'avantage qu'on ne peut lui répondre. Que faire alors sinon te prier de recevoir mes remerciements à la place de l'ange"5 (BENJAMIN, p. 246, apud WEIGEL, 2010, p. 7).

Contudo, o que mais nos chama atenção na alegoria é a descrição metafórica da modernidade, tendo como cenário a cidade, além da expressão do Anjo da História, com a boca aberta, os olhos arregalados e olhar cravado, "marcado por uma dor profunda e inconsolável - mas também por uma profunda revolta moral" (LÖWY, 2005, p.92). O desejo de acordar os mortos e não perder de vista os escombros, explicita o perigo: de perder vozes que se atualizam em um presente revolucionário; de não haver mais experiências comunicáveis; da destruição de uma memória, passada de geração para geração, que pode levar o ser humano a agir historicamente. A "pobreza de experiências é apenas parte da grande pobreza" e entre esses escombros, uma nova miséria, trazida pelo progresso, the é peculiar, o "monstruoso desenvolvimento da técnica, sobrepondo-se ao homem" (BENJAMIN, 1994b, p.115).

\section{A cidade moderna como cenário: fantasmagoria e pobreza de experiências}

A cidade como vitrine da sociedade moderna, palco do "universo de uma fantasmagoria", incentiva o individualismo, aquele ancorado na dimensão privada da experiência, mergulhada na lógica capitalista. Esta ilusão parece ter influência do desenvolvimento da técnica (da tecnização, do aumento da virtualidade técnica) e do desenvolvimento econômico (a impregnação do

\footnotetext{
5 "Eu tenho dito uma palavra sobre sua "saudação"? A língua angelical conta entre suas maravilhas a vantagem de que não podemos respondê-la. O que fazer então, senão te pedir para receber meus agradecimentos no lugar do anjo" (tradução nossa).
}

Mestre e doutorando em Educação. Professor da Universidade Federal de Alagoas (UFAL), Campus Arapiraca. Integrante do Grupo de Estudo e Pesquisa História da Educação, Cultura e Literatura (GEPHECL) do Centro de Educação/UFAL. Brasileiro, residente em Maceió-AL. Email: rafaelbelo paz@hotmail.com 
capitalismo na cidade, uma crescente fantasmagoria do mercado) (BENJAMIN, 2007a, 2007b).

Disso resulta a cidade como cenário do empobrecimento da experiência em seu caráter coletivo (Erfahrung), aquela experiência partilhada que apresenta uma memória também coletiva.

Jeanne Marie Gagnebin $(1994,9)$ destaca que:

\begin{abstract}
Nos textos fundamentais dos anos 30, (...), Benjamin retoma a questão da "Experiência", agora dentro de uma nova problemática: de um lado, demonstra o enfraquecimento da "Erfahrung" no mundo capitalista moderno em detrimento de um outro conceito, a "Erlebnis", a experiência vivida, característica do sujeito solitário (...).
\end{abstract}

A vida na cidade moderna propicia o predomínio da privaticidade da experiência (Erlebnis), assim como o predomínio da informação, em detrimento do cultivo da sabedoria. Podemos atribuir a essa experiência individualizada imersa na lógica capitalista o nome de "fantasmagoria". A modernidade, acentua, pois, o mundo privado, as fantasmagorias do interior, da interioridade.

Benjamin critica a experiência urbana moderna, posto que as características e o ritmo acelerado da cidade moderna levariam ao empobrecimento da dimensão coletiva da experiência, contrapondo-se, por exemplo, ao ritmo da narrativa tradicional e contribuindo para o desaparecimento da figura do narrador, aquele que recorre ao acervo de uma vida que vai além da sua memória individualizada. Assim, de acordo com o próprio, o trabalho de Benjamin

(...) procura mostrar como, em consequência dessa representação coisificada da civilização, as formas de vida nova e as novas criações de base econômica e técnica, que devemos ao século XIX, entram no universo de uma fantasmagoria (BENJAMIN, 2007b, 53).

Paris é tomada como cidade símbolo dessa modernidade no século XIX em sua obra Passagens.

As passagens são o centro das mercadorias de luxo. Para expô-las, a arte põe-se a serviço do comerciante. Os contemporâneos não se cansam de admirá-las. Durante muito tempo permanecerão uma atração para os forasteiros (BENJAMIN, 2007a, 40).

Mestre e doutorando em Educação. Professor da Universidade Federal de Alagoas (UFAL), Campus Arapiraca. Integrante do Grupo de Estudo e Pesquisa História da Educação, Cultura e Literatura (GEPHECL) do Centro de Educação/UFAL. Brasileiro, residente em Maceió-AL. Email: rafaelbelo paz@hotmail.com 
As passagens são como símbolo do empobrecimento da condição humana, ao contrário do que prega o progresso. O surgimento das passagens ou das galerias, estes centros comerciais de mercadorias de luxo, foram propiciadas pela alta no comércio têxtil e pelos primórdios das construções de ferro.

No texto Paris, Capital do século XIX, Benjamin (2007a) descreve a modernização da capital francesa. A arquitetura começa a se emancipar da arte e há uma aceleração da vida na cidade.

A vida na grande cidade potencializa esses efeitos de aceleração e de anonimato pela rapidez dos transportes, dos encontros, e pela aglutinação de pessoas em espaços apertados de trabalho e de moradia (GAGNEBIN, 2014, 14).

Destaca-se que as mudanças urbanísticas implementadas por Haussmann fizeram com que Paris se tornasse uma cidade estranha para os próprios parisienses.

O aumento dos aluguéis impele o proletariado para os subúrbios. Com isso, os bairros de Paris perdem sua fisionomia própria. Surge o 'cinturão vermelho' operário. Haussmann denomina a si mesmo de 'artista demolidor'. Sentia-se predestinado à sua obra, fato que enfatiza em suas memórias. Entretanto, provoca nos parisienses estranhamento em relação à sua cidade. Nela não se sentem mais em casa. Começam a tomar consciência do caráter desumano da grande cidade (BENJAMIN, 2007a, 49).

\section{A (nova) barbárie como ato criador}

Deste cenário empobrecido, Benjamin (1994b, 115) pergunta: "Pois qual o valor de todo o nosso patrimônio cultural, se a experiência não mais o vincula a nós?".

Essa desvinculação, poderíamos dizer falta de inteireza, desconexão, desintegração, é também uma característica, ou consequência, da modernidade. É claro que isso não está facilmente anunciado aos olhos modernos, visto que é a todo tempo disfarçado em fantasmagorias, em um jogo de falsas renovações. Contudo, a distinção é mais fácil do se imagina: o novo não pode surgir de uma dicotomia experiencial, do contrário não passará de uma mera "galvanização". 
Para explicar, Benjamin evoca as imagens ${ }^{6}$ de um pintor belga, precursor do expressionismo e do surrealismo:

Pensemos nos esplêndidos quadros de Ensor, nos quais uma grande fantasmagoria enche as ruas das metrópoles: pequeno-burgueses com fantasias carnavalescas, máscaras disformes brancas de farinha, coroas de folha de estanho, rodopiam imprevisivelmente ao longo das ruas. Esses quadros são talvez a cópia da Renascença terrível e caótica na qual tantos depositam suas esperanças (BENJAMIN, 1994b, 115).

O citado pintor, James Ensor, viveu entre os anos de 1860 e 1949, e possui como marca de sua arte a crítica político-social, além da presença das multidões e das máscaras como elemento recorrente em suas pinturas. De acordo com Herwig Todts (s.d), Ensor não pode ser considerado um proponente imparcial do Modernismo, devido sobretudo à sua suspeita dos ideais lluministas e dúvidas sobre a bondade do ser humano. Para tal análise, além das obras, Todts (s.d) estudou seus escritos, entre eles cerca de 900 cartas e diversas publicações em jornais ou brochuras. De forma que, para o pesquisador, o nível modernista de Ensor é superestimado e sua arte é "ocasionalmente modernista". Entende ainda que, de acordo com a definição do historiador literário francês Antoine Compagnon, Ensor poderia até ser chamado de "anti-moderno". Para Compagnon (apud TODTS, s.d), um dos aspectos da arte dos séculos XIX e XX é a corrente "anti-moderna", no qual inclui intelectuais que se opõem à crença cega na razão e no cultivo e bênçãos da igualdade social. Entre estes, Compagnon (apud TODTS, s.d) inclui Baudelaire, que teria sido simultaneamente repelido e atraído pela inovação nas artes e na sociedade.

Na fantasmagoria, percebida por Benjamin nos quadros de Ensor, há a celebração da esperança na modernidade pela multidão empobrecida. Não se espere, contudo, que esses modernos moradores da cidade aspirem a novas experiências:

Não, eles aspiram libertar-se de toda experiência, aspiram a um mundo em que possam ostentar tão pura e tão claramente sua pobreza externa e interna, que algo de decente possa resultar disso (BENJAMIN, 1994b, 118).

\footnotetext{
${ }^{6} \mathrm{https}: / /$ www.sartle.com/artwork/self-portrait-with-masks-james-ensor
}

Mestre e doutorando em Educação. Professor da Universidade Federal de Alagoas (UFAL), Campus Arapiraca. Integrante do Grupo de Estudo e Pesquisa História da Educação, Cultura e Literatura (GEPHECL) do Centro de Educação/UFAL. Brasileiro, residente em Maceió-AL. Email: rafaelbelo paz@hotmail.com 
Seriam então, por isso, "ignorantes" e "inexperientes"? Não, há entre esses homens aqueles que Nietzsche (1999) chamaria de supra-históricos. Estes são aqueles que desmedidamente se alimentam do saber e da cultura histórica, sem que haja uma elaboração existencial de suas experiências.

Em seu ensaio de 1874, Da utilidade e desvantagem da história para a vida, Nietzsche critica o homem moderno e a supervalorização do saber teórico em detrimento da afirmação experiencial da vida. Sobre esse homem suprahistórico, um típico homem moderno, o filósofo diz o seguinte:

O homem moderno acaba por arrastar consigo, por toda parte, uma quantidade descomunal de indigestas pedras de saber, que ainda, ocasionalmente, roncam na barriga, como se diz no conto. Com esses roncos denuncia-se a propriedade mais própria desse homem moderno: a notável oposição entre um interior, a que não corresponde nenhum exterior, e um exterior, a que não corresponde nenhum interior, oposição que os povos antigos não conhecem. O saber, que é absorvido em desmedida sem fome, e mesmo contra a necessidade, já não atua mais como motivo transformador, que impele para fora, e permanece escondido em um certo mundo interior caótico, que esse homem moderno, com curioso orgulho, designa como a "interioridade" que lhe é própria (NIETZSCHE, 1999, 278).

Ao nosso ver, existe uma grande proximidade nas metáforas utilizadas por Nietzsche para descrever este homem moderno, e aquelas utilizadas por Benjamin para demonstrar que em meio à pobreza de experiência da modernidade, nem todos são "ignorantes" ou "inexperientes":

\begin{abstract}
Muitas vezes, podemos afirmar o oposto: eles 'devoraram' tudo, a 'cultura' e os 'homens', e ficaram saciados e exaustos. (...) Ao cansaço segue-se o sonho, e não é raro que o sonho compense a tristeza e o desânimo do dia, realizando a existência inteiramente simples e absolutamente grandiosa que não pode ser realizada durante o dia, por falta de forças (BENJAMIN, 1994b, 218).
\end{abstract}

Em ambos, fala-se de uma certa dificuldade de digerir o que foi devorado em demasia, o saber, a história, a cultura. A indigestão ou esse cansaço depois de se alimentar indica uma dificuldade de elaboração da experiência, de vincular esse alimento a si, ou de ir além da experiência individualizada ou da mera interioridade.

O ensaio de Nietzsche é citado por Benjamin na epígrafe da tese XII, e de acordo com Löwy $(2005,72-73)$ a obra foi lida, admirada e serviu de inspiração:

Mestre e doutorando em Educação. Professor da Universidade Federal de Alagoas (UFAL), Campus Arapiraca. Integrante do Grupo de Estudo e Pesquisa História da Educação, Cultura e Literatura (GEPHECL) do Centro de Educação/UFAL. Brasileiro, residente em Maceió-AL. Email: rafaelbelo paz@hotmail.com 
Nietzsche simplesmente sentia desprezo pelos historiadores que "nadam e se afogam no rio do futuro", que praticam "a admiração nua do sucesso" (nackte Bewnderung des Erfolges) e "a idolatria do factual" (Götzendienst des Tatsächliches); em suma, que dizem sempre "sim" com a cabeça para todo poder, de maneira "chinesa mecânica". Para ele, o diabo é o verdadeiro senhor do sucesso e do progresso: a virtude, para o historiador, consiste em se opor à tirania do real, a "nadar contra as ondas da história" e em saber lutar contra elas.

Diferença decisiva entre esses dois pensadores, segundo Löwy (2005, 73), é que

(...) a crítica de Nietzsche é feita em nome do indivíduo rebelde, o herói - mais tarde, o super-homem. A de Benjamin, ao contrário, é solidária aos que caíram sob as rodas de carruagens majestosas e magníficas denominadas Civilização, Progresso e Modernidade.

Existe um importante conceito elaborado por Benjamin que parece ter uma significativa influência de Nietzsche: o "conceito novo e positivo de barbárie", presente no texto Experiência e Pobreza, escrito em 1933. Com a confissão da subtração da experiência coletiva, o reconhecimento do empobrecimento não apenas na experiência privada, mas da humanidade em geral, surge para Benjamin (1994b) uma nova barbárie.

Pois o que resulta para o bárbaro dessa pobreza de experiência? Ela o impele a partir para frente, a começar de novo, a contentar-se com pouco, a construir com pouco, sem olhar nem para a direita nem para a esquerda. Entre os grandes criadores sempre existiram homens implacáveis que operaram a partir de uma tábula rasa (BENJAMIN, 1994b, 115).

Entende-se que o "bárbaro" deste "conceito novo e positivo de barbárie" tem uma relação com o "homem histórico" descrito por Nietzsche nas Considerações extemporâneas. Diferentemente do "homem supra-histórico", o "homem histórico" é aquele que, em um dado sentido de esquecimento, age ahistoricamente. Sem o peso determinista do passado, esse homem histórico pode criar sua história, sendo capaz de transformar a história em obra de arte.

Esse criador, impelido a começar novamente, Benjamin o reconhece como um novo bárbaro. Aquele que, ao invés de se conformar com o contínuo dos acontecimentos, torna-se parte da ruptura, da reinvenção, poderíamos dizer que de uma certa contracultura. Sua força nasce de um agir a-histórico.

Mestre e doutorando em Educação. Professor da Universidade Federal de Alagoas (UFAL), Campus Arapiraca. Integrante do Grupo de Estudo e Pesquisa História da Educação, Cultura e Literatura (GEPHECL) do Centro de Educação/UFAL. Brasileiro, residente em Maceió-AL. Email: rafaelbelo paz@hotmail.com 
Como criadores, Benjamin (1994b, 116) cita Descartes, que "baseou sua filosofia em uma única certeza - penso, logo existo - e dela partiu", e Einstein, que, tendo perdido o interesse por todo o universo da Física, se concentrou em único problema, "uma pequena discrepância entre as equações de Newton e as observações astronômicas". Entre esses criadores, que tinham em mente essa mesma preocupação de começar do princípio, Benjamin cita também os artistas propriamente ditos como: os cubistas; o poeta Bertolt Brecht; o precursor da nova arquitetura Adolf Loos; o pintor Paul Klee, caracterizado como complexo; o escritor alemão Paul Scheerbart.

Apesar de apresentar a importância do caráter criador dado ao novo bárbaro, Benjamin não aprofunda a discussão da dimensão política no texto Experiência e Pobreza. Este texto, colocando-se de forma fortemente provocativa e, possivelmente de modo intencional, mantém-se aberto para a interpretação dos leitores que, por sua vez, precisarão dialogar com outros escritos do autor para chegar à compreensão pretendida. Em nossas problematizações, por exemplo, nos parece que nem todos que podem ser apontados como grandes criadores, mantêm, necessariamente, uma ética político-revolucionária, no sentido messiânico inclusive, como apresentado nas famosas teses Sobre o conceito de história. Não está claro, também, em que medida uma descoberta, uma técnica ou produto, que parte de uma tábula rasa, ou que é construído com pouco, possa também servir à cultura do progresso. Assim como não é explicitada a relação entre o novo bárbaro e as vozes do passado, vindas dos escombros e ruínas típicos da modernidade.

Por outro lado, é importante destacar que para resistir à cultura que produz "amontoados de ruínas", numa "tempestade" que "chamamos de progresso", é preciso sermos criadores, sobreviver à cultura e, o que Benjamin afirma ser o mais importante, fazê-lo rindo, pois talvez aqui e ali esse riso tenha um som bárbaro (BENJAMIN, 1994b). Entre esses, há artistas que, mesmo mergulhados no cotidiano das cidades modernas, colocam-se contrários à correnteza de destruição e afirmam a nova barbárie como ato criador. 


\section{0 artista na cidade moderna}

"As ruas

que me foram passagens agora me são inéditas.

Suas peculiaridades

por mais contraditórias

são apaixonantes

como tudo que sou capaz de enxergar".

(Rafael A. Belo, fragmento da poesia 'Na madrugada descalça de Maceió', 2010)

O novo bárbaro tão necessário na cidade moderna, com sua capacidade de criação, é alguém que, para Benjamin (1994b), se caracteriza por uma desilusão radical com sua época, ao mesmo tempo que tem uma fidelidade sem reservas a ela. De certo modo, assim também é o novo artista que surge na cidade moderna.

Benjamin (2007a) destaca a figura de Baudelaire, por quem pela primeira vez Paris se torna objeto da poesia lírica. Esse também apresenta os seus personagens, sem os quais a cidade não pode ser pensada como tema de sua poesia. Tem-se aí o surgimento do artista próprio da cidade moderna. A arte de Baudelaire, sua poesia criada no espaço urbano, o qual é feito para ali reinar o fetiche da mercadoria, extrai sua força do pathos da rebelião do proletariado. Seu olhar é o do alegórico, do estranhamento, do flâneur, que ora tem na multidão sua paisagem, ora ninho acolhedor. "Baudelaire é um exemplo das dificuldades da lírica sob o capitalismo avançado, como o chama Benjamin, mas também de suas transformações possíveis, de um novo tipo de 'beleza' ou de 'arte', portanto" (GAGNEBIN, 2014, 15).

Charles Baudelaire, poeta que teria sido o tipo de artista próprio da modernidade, capaz de criar e encontrar sua arte na afirmação da vida na cidade. Seus versos vão ao fragmento, ao ordinário da vida cotidiana, ao que seria desprezível aos artistas da "arte das coisas eternas e duradouras". Talvez por isso, por ter tido de experimentar criativamente a cidade moderna, como fonte de sua arte, ele tenha chamado tanto a atenção de Benjamin. 
Segundo Benjamin (2000, p.5), "a imagem do artista de Baudelaire aproxima-se da imagem do herói. Eles se equivalem mutuamente desde o início". Para ele, "o herói é o verdadeiro tema da modernité. Isso significa que para viver a modernidade é preciso uma formação heroica" (BENJAMIN, 2000, 9).

De acordo com o filósofo, esta nova versão, não romântica, do herói é dada tanto por Baudelaire, que reconhece no "proletariado o escravo da esgrima", como por Balzac, onde o gladiador torna-se "commis voyageur", o caixeiro viajante. "Aquilo que o assalariado realiza no trabalho diário não é menos importante que o aplauso e a glória do gladiador na antiguidade" (BENJAMIN, 2000, 11).

O herói na modernidade, portanto, é um cidadão comum, que torna heroico os acontecimentos de sua existência. Ele não é o herói em si, mas alguém que ousa assumir este papel, tornando-se representante do herói. Nas palavras de Benjamin (2000, p. 29): "Porque o herói moderno não é herói — é o representante do herói. A modernidade heróica revela-se como tragédia em que o papel do herói está disponível". O próprio Baudelaire era assim, de modo que o flaneur, o apache, o dândi e o trapeiro eram somente diferentes papéis. O que, para Benjamin (2000), demonstrava uma falta de convicção de Baudelaire.

Para Baudelaire "nada se aproxima tanto da 'tarefa' do herói antigo, dos 'trabalhos' de um Hércules, como a tarefa de que ele próprio se impôs: dar feição à modernidade" (BEMJAMIN, 2000, 16).

Assim, o artista que na modernidade pode ser chamado de herói não será aquele que lida exclusivamente com as coisas eternas e imutáveis, e sim aquele que tem seu trabalho marcado pela vida na cidade. Nessa compreensão, Baudelaire (1996, p.859) irá definir que "a modernidade é o transitório, o efêmero, o contingente, é a metade da arte, sendo a outra metade o eterno e o imutável".

Baudelaire representaria o declínio da figura tradicional do artista. O artista seria um anônimo que, na cidade moderna, perdera sua aura. "Em suma, o que é aura? É uma figura singular, composta de elementos espaciais e temporais: a aparição única de uma coisa distante, por mais perto que ela esteja" (BENJAMIN, 1994d, 170). 
Contudo, o poeta, ou o artista, nem sempre assume em seu ofício temas realmente heroicos:

A maioria dos poetas que trataram de assuntos realmente modernos contentou-se com temas estereotipados, oficiais - estes poetas preocupam-se com nossas vitórias e nosso heroísmo político. Mas fazem-no também de mau grado, e apenas porque o governo o ordena e lhes paga. Mas existem temas da vida privada muito mais heroicos. O espetáculo da vida mundana e de milhares de existências desordenadas; vivendo nos submundos de uma grande cidade - dos criminosos e das prostitutas - A 'Gazette des Tribunaux' e o 'Moniteur' provam que apenas precisamos abrir os olhos para reconhecer o heroísmo que possuímos (BAUDELAIRE, apud BENJAMIN, 2000, 14).

Pode-se observar uma relação entre o poeta, artista herói de Baudelaire e o bárbaro de Benjamin, quando esse artista é descrito como alguém que cria a partir de pouco, tal qual um trapeiro.

Os poetas encontram na rua o lixo da sociedade e a partir dele fazem sua crítica heroica. Parece que assim se integra no seu ilustre tipo um tipo semelhante, penetrado pelos traços do trapeiro que tanto preocupava Baudelaire. (...) Esta descrição é uma única, longa metáfora, para o procedimento do poeta segundo o coração de Baudelaire. Trapeiro ou poeta - o lixo se refere a ambos; ambos realizam solitariamente seu trabalho a horas em que os burgueses dormem; o gesto é o mesmo em ambos. Há fortes indícios de que Baudelaire pretendia veladamente chamar a atenção sobre este parentesco (BENJAMIN, 2000, 14-15).

O artista em Baudelaire também possui algo do flêneur:

Para o perfeito flâneur, para o observador apaixonado, é um imenso júbilo fixar residência no numeroso, no ondulante, no movimento, no fugidio e no infinito. Estar fora de casa, e contudo sentir-se em casa onde quer que se encontre; ver o mundo, estar no centro do mundo e permanecer oculto ao mundo, eis alguns dos pequenos prazeres desses espíritos independentes, apaixonados imparciais, que a linguagem não pode definir se não toscamente (BAUDELAIRE, 1996, 857).

Há, contudo, diferenças entre o artista e o flâneur:

Certamente esse homem, tal como o descrevi, esse solitário dotado de uma imaginação ativa, sempre viajando através do grande deserto de homens, tem um objetivo mais elevado do que a de um simples flâneur, um objetivo mais geral, diverso do prazer efêmero da circunstância. Ele busca esse algo, ao qual se permitirá chamar de modernidade, pois não me ocorre melhor palavra para exprimir a ideia em questão" (BAUDELAIRE, 1996, 859).

Mestre e doutorando em Educação. Professor da Universidade Federal de Alagoas (UFAL), Campus Arapiraca. Integrante do Grupo de Estudo e Pesquisa História da Educação, Cultura e Literatura (GEPHECL) do Centro de Educação/UFAL. Brasileiro, residente em Maceió-AL. Email: rafaelbelo paz@hotmail.com 
Em um texto escrito ao longo da década de 60 do século XIX, O pintor da vida moderna, Baudelaire apresenta aspectos caracterizadores da modernidade. Tomando como referência a vida do pintor Constantin Guys, ele descreve o artista que emerge na modernidade, "homem do mundo, isto é, homem do mundo inteiro, homem que compreende o mundo e as razões misteriosas e legítimas de todos os seus costumes(...)" (BAUDELAIRE, 1996, 855), que toma a multidão como casa.

Constantin Guys foi um pintor que começou a pintar tardiamente, possivelmente, de acordo com Baudelaire (1996), por volta dos quarenta anos. Nasceu no ano de 1802, em uma cidade a sudoeste dos Países Baixos, e morreu em 1892 em Paris, onde passou a maior parte da sua vida e onde assumiu 0 ofício da arte. Embora não gostasse de ser chamado de artista, no seu sentido clássico. Baudelaire (1996, p. 855) explica a razão: "Ele se interessava pelo mundo inteiro; quer saber, compreender, apreciar tudo o que acontece na superfície de nosso esferoide. O artista vive pouquíssimo - ou até não vive - no mundo moral e político".

Sobre o processo criativo de Constantin Guys, Baudelaire comenta:

Contempla as paisagens da cidade grande, paisagens de pedra acariciadas pela bruma ou fustigadas pelos sopros do sol. Admira as belas carruagens, os garbosos cavalos, a limpeza reluzente dos lacaios, a destreza dos criados, o andar das mulheres ondulosas, as belas crianças, felizes por viverem e estarem bem vestidas; resumindo, a vida universal. (...) Mas a noite chegou. (...) Os revérberos se sobressaem sobre a púrpura do poente. (...) Os plácidos e os de má índole pensam no prazer e todos acorrem ao lugar de sua preferência para beber a taça do esquecimento. Constantin Guys será o último a partir de qualquer lugar onde possa resplandecer a luz, ressoar a poesia, fervilhar a vida, vibrar a música; de todo lugar onde uma paixão possa posar para seus olhos, de todo lugar onde o homem natural e 0 homem convencional se mostrem numa beleza estranha, de todo lugar onde o sol ilumina as alegrias efêmeras do animal depravado. (...) Agora, à hora em que os outros estão dormindo, ele está curvado sobre sua mesa lançando sobre uma folha de papel o mesmo olhar que há pouco dirigia às coisas, lutando com seu lápis, sua pena, seu pincel, lançando a água do copo até o teto, limpando a pena na camisa, apressado, violento, ativo, como se temesse que as imagens the escapassem, belicoso, mas sozinho e debatendo-se consigo mesmo. $E$ as coisas renascem no papel, naturais e, mais do que naturais, belas; mais do que belas, singulares e dotadas de uma vida entusiasta como

Mestre e doutorando em Educação. Professor da Universidade Federal de Alagoas (UFAL), Campus Arapiraca. Integrante do Grupo de Estudo e Pesquisa História da Educação, Cultura e Literatura (GEPHECL) do Centro de Educação/UFAL. Brasileiro, residente em Maceió-AL. Email: rafaelbelo paz@hotmail.com 
a alma do autor. A fantasmagoria foi extraída da natureza (BAUDELAIRE, 1996, 858-859).

Um pintor de costumes, assim era considerado Constantin Guys. Seus temas retrataram a época ${ }^{7}$. Neste sentido, pode-se dizer que há semelhanças com Baudelaire, pois esse poeta "pinta" o que se pode chamar de modernidade.

\section{CONCLUSÃO}

\section{A arte e 0 artista em Walter Benjamin: a política e a função revolucionária da arte}

A compreensão da arte ou do artista nos escritos de Walter Benjamin não pode se isentar de suas implicações políticas, e até mesmo messiânicas, no contexto da modernidade.

Esse contexto pode ser descrito de forma mais explícita na alegoria sobre - Anjo da História, uma interpretação no quadro de Paul Klee. A cena é catastrófica. Uma barbárie consequente da cultura de exploração e dominação no âmbito do capitalismo. A destruição da memória e da experiência coletiva, assim como do poder revolucionário e da capacidade de agir historicamente, faz parte desta contextualização.

Esta mesma modernidade pode também ser descrita através do universo de uma fantasmagoria: a experiência privada imersa na lógica capitalista. A cidade como símbolo, disfarçando o empobrecimento humano com ajuda da técnica. As passagens expondo mercadorias de luxo e arrancando os olhares dos modernos. A imagem sugerida por Benjamin são os quadros de James Ensor, com burgueses mascarados em multidões festejantes. Supostamente uma crítica à esperança iluminista instalada na modernidade.

Dadas as imagens que descrevem esse cenário, faz-se necessário o surgimento do novo bárbaro, capaz de resistir a essa cultura e criar entre os escombros. Esse bárbaro não é necessariamente um artista no sentido formal, podemos entendê-lo como um ser humano comum capaz de agir historicamente a partir do pouco que Ihe resta, por isso, em certa medida, capaz de agir a-

\footnotetext{
${ }^{7}$ https://www.louvre.fr/en/oeuvre-notices/equipage-park

Mestre e doutorando em Educação. Professor da Universidade Federal de Alagoas (UFAL), Campus Arapiraca. Integrante do Grupo de Estudo e Pesquisa História da Educação, Cultura e Literatura (GEPHECL) do Centro de Educação/UFAL. Brasileiro, residente em Maceió-AL. Email: rafaelbelo paz@hotmail.com
} 
historicamente. Assim podemos relacionar o "novo bárbaro" de Benjamin com o "homem histórico" de Nietzsche. Ainda que esse bárbaro não tenha a arte como ofício, ele será artista de sua existência; nos termos da psicologia fenomenológica existencial seria o criador dialógico de si e do mundo que o cerca.

No entanto, o artista, no sentido formal, também pode ser um novo bárbaro, embora não necessariamente. A diferença está no sentido político da sua arte. O artista, quando se assume bárbaro, está disposto a sobreviver à cultura moderna. Assim não será aquele que se vangloriará por produzir coisas eternas. Sua "desilusão radical" com sua época o lança a nadar contra a correnteza ditada pelo progresso, produzindo, de certo modo, uma contracultura. Os elementos de sua criação encontram-se no cotidiano da cidade, em seus fragmentos, os mesmos que são desprezados pelos ditos grandes artistas clássicos. Por isso, pode-se dizer que há certo heroísmo nesse artista moderno por se propor a assumir anonimamente esse papel.

O poeta Charles Baudelaire é certamente símbolo desse artista na metrópole. Benjamin reconhece em Baudelaire a arte de tomar a cidade e seus personagens como símbolo de sua poesia. Por outro lado, também tece críticas: "A teoria da arte moderna é o ponto mais fraco na concepção de Baudelaire sobre a modernidade (...)" (BENJAMIN, 2000, 17). Segundo Benjamin (2000), sua teoria "não dominou a renúncia", que aparece em sua obra como a "perda da natureza e perda da ingenuidade".

\begin{abstract}
Em resumo, a doutrina se apresenta da seguinte forma: 'Na beleza colaboram um elemento eterno, imutável e um elemento relativo, limitado. Este último é condicionado pela época, pela moda, pela moral, pelas paixões. O primeiro elemento não seria assimilável sem este segundo elemento'. Não se pode dizer que isto seja profundo (BENJAMIN, 2000, 16-17).
\end{abstract}

Supostamente, a fraqueza da teoria da arte de Baudelaire tenha a ver com a concepção não aprofundada de tempo, não abarcando o espiritual, o messiânico, o momento em que passado e presente se unem como um lampejo.

A arte, no sentido de uma nova e positiva barbárie, deve proporcionar a experiência messiânica de ruptura, na medida em que encorpa uma luta que não é somente sua e de sua geração, mas também de gerações passadas. Pois isso, 
para Benjamin (1994b, 119), os bárbaros precisam instalar-se: "São solidários dos homens que fizeram do novo uma coisa essencialmente sua, com lucidez e capacidade de renúncia".

Entre os novos bárbaros, Benjamin (1994b) cita o poeta e dramaturgo alemão Bertolt Brecht, que viveu entre os anos de 1898 e 1956. Foi grande amigo de Benjamin, tendo exercido para ele uma importante influência marxista. Desenvolveu o chamado teatro épico, tema sobre o qual Benjamin escreveu em um artigo em 1931: O que é o teatro épico? Um estudo sobre Brecht. Segundo Flávio Kothe $(1991,21)$, "Brecht e o teatro épico representam um grau de consciência política que Baudelaire não alcançara, levando este a colocar muitos aspectos da realidade sob a forma de fantasmagoria (...)". Benjamin (1994c, 81) compreende que "o teatro épico se dirige a indivíduos interessados, que 'não pensam sem motivo'. (...) Em consequência, o teatro não reproduz condições, mas descobre".

A intencionalidade da arte e o poder de ação política do artista demonstram ser algo primordial para Benjamin. Além do texto sobre Brecht, o aspecto político relacionado à arte também é discutido em textos como $O$ Surrealismo: O último instantâneo da inteligência europeia, e $A$ obra de arte na era de sua reprodutividade técnica. Neste último, o autor chama a atenção do risco da arte ser utilizada pelo fascismo, sobretudo a partir do "desenvolvimento das técnicas de reprodução e registro". Fazendo uma referência mais específica ao cinema, Benjamin (1994d, 194) afirma que "a reprodução em massa corresponde de perto à reprodução das massas". Mantém-se, assim, as relações de exploração.

A arte pela arte, por outro lado, também não terá uma função no bom sentido de barbárie. Para Benjamin (1994d, 171), "a doutrina da arte pela arte" é no fundo "uma teologia da arte". Em contraposição, "o teatro épico questiona o caráter de diversão atribuído ao teatro. Abala sua validade social ao privá-lo de sua função na ordem capitalista" (BENJAMIN, 1994c, 86).

No texto sobre o surrealismo, publicado em 1929, Benjamin (1994e, 28) destaca o caminho percorrido pelo surrealismo até sua politização: a "transformação de uma atitude extremamente contemplativa em uma oposição 
revolucionária". Para o autor, nessa transformação, "a hostilidade da burguesia contra toda manifestação da liberdade espiritual desempenha um papel decisivo. Foi essa hostilidade que empurrou para a esquerda o surrealismo". Para Benjamin (1994e, p.35), os surrealistas teriam compreendido a exigência, expressa no Manisfesto comunista, de que "todas as tensões revolucionárias se transformem em inervações do corpo coletivo, e todas as inervações do corpo coletivo se transformem em tensões revolucionárias".

Ainda na primeira metade do século XX, Benjamin (1994d, 196) observou que a humanidade chegou em um ponto de autoalienação que sua própria destruição está vivida como "um prazer estético de primeira ordem. Eis a estetização da política, como a pratica o fascismo". A atualidade de pensamento torna-se assustadora, pois nos dias de hoje as posturas que tendem ao fascismo renascem, aproximando-nos cada vez mais de novas guerras.

Assim, nesta modernidade que avança pelo século XXI, urge o surgimento de muitos novos bárbaros. Dentre esses, precisamos também de artistas que possam responder com a "politização da arte".

\section{Dedicatória}

Dedico este artigo à Prof. Drª Maria das Graças Loiola Madeira, pelo cultivo de reflexões atualizadas em torno dos escritos de Walter Benjamin.

\section{REFERÊNCIAS}

BAUDELAIRE, Charles. As flores do mal. Edição bilíngue. Rio de Janeiro: Nova Fronteira, 2012.

. O pintor da vida moderna. In__: Poesia e prosa. Rio de Janeiro: Nova Aguilar, 1996. p. 851-881.

BENJAMIN, Walter. Paris, A capital do século XIX. <Exposé de 1935> In

Passagens. Belo Horizonte: Editora da UNMG, 2007a, p. 39-51.

. Capital do século XIX. <Exposé de 1939> In : Passagens. Belo Horizonte: Editora da UFMG, 2007b, p. 53-67. 
Sobre o conceito de história. In : LÖWY, Michel. Walter Benjamin: aviso de incêndio. Uma leitura das teses "Sobe o conceito de história". Tradução de Jeanne Marie Gagnebin e Marcos Lutz Müller. São Paulo: Boitempo, 2005.

A modernidade e os modernos. $2^{a}$ ed. Rio de Janeiro, RJ: Tempo Brasileiro, 2000.

. Sobre o conceito de História. In_: Magia e técnica, arte e política. Obras escolhidas vol. 1. São Paulo: Brasiliense, 1994a. p. 222 - 232

. Experiência e pobreza. In _ : Magia e técnica, arte e política. Obras escolhidas vol. 1. São Paulo: Brasiliense, 1994b. p. 114 - 119

Que é o teatro épico? Um estudo sobre Brecht. In__: Magia e técnica, arte e política. Obras escolhidas vol. 1. São Paulo: Brasiliense, 1994c. p. 78 - 90

. A obra de arte na era de sua reprodutividade técnica. Um estudo sobre Brecht. In_: Magia e técnica, arte e política. Obras escolhidas vol. 1. São Paulo: Brasiliense, 1994d. p. 165 -196

. O surrealismo. O último instantâneo da inteligência europeia. In Magia e técnica, arte e política. Obras escolhidas vol. 1. São Paulo:

Brasiliense, 1994e. p. 21 -35

GAGNEBIN, Jeanne Marie. Prefácio. REDOBRA, n.14, ano 5, p. 7-17, 2014. ISSN 2238-3794. Disponível em: http://www.redobra.ufba.br/. Acesso em: 9 out. 2016

. Prefácio. Walter Benjamin ou a história aberta. In_ : BENJAMIN, Walter. Magia e técnica, arte e política: ensaios sobre literatura e história da cultura. Tradução de Sérgio Paulo Rouanet. 7.ed. São Paulo: Brasiliense, 1994. p. 7-19

JUNQUEIRA, Ivan. Introdução. In_ : BAUDELAIRE, Charles. As flores do mal. Edição bilíngue. Rio de Janeiro: Nova Fronteira, 2012.

KOTHE, Flávio R. Poesia e proletariado: ruínas e rumos da história. In_: (Org.). Walter Benjamin: sociologia. 2.ed. São Paulo: Ática, 1991. p.8-27

LÖWY, Michel. Walter Benjamin: aviso de incêndio. Uma leitura das teses "Sobe o conceito de história". São Paulo: Boitempo, 2005.

NIETZSCHE, Friedrich. Considerações extemporâneas. II - Da utilidade e desvantagem da história para a vida. In _ : Obra incompletas. Coleção Os Pensadores. São Paulo: Editora Nova Cultural, 1999. p.273-298.

TODTS, Herwig. Ensor, ocasional modernista, s.d. In_ : James Ensor. An online museum. Disponível em:

http://jamesensor.vlaamsekunstcollectie.be/en/sources/online-

publications/ensor-occasional-modernist. Acesso em: 07 de nov. 2018.

Mestre e doutorando em Educação. Professor da Universidade Federal de Alagoas (UFAL), Campus Arapiraca. Integrante do Grupo de Estudo e Pesquisa História da Educação, Cultura e Literatura (GEPHECL) do Centro de Educação/UFAL. Brasileiro, residente em Maceió-AL. Email: rafaelbelo paz@hotmail.com 
WEIGEL, Sigrid. Les chefs-d'œuvre inconnus dans la galerie d'images de Walter Benjamin. Sur l'importance de l'art pour l'épistémologie benjaminienne. Images Re-vues: histoire, anthrologie et théorie de l'art. Série especial 2, jan, 2010. Disponível em: http://journals.openedition.org/imagesrevues/431. Acesso: 9 set. 2018.

Mestre e doutorando em Educação. Professor da Universidade Federal de Alagoas (UFAL), Campus Arapiraca. Integrante do Grupo de Estudo e Pesquisa História da Educação, Cultura e Literatura (GEPHECL) do Centro de Educação/UFAL. Brasileiro, residente em Maceió-AL. Email: rafaelbelo paz@hotmail.com 